\title{
ACCURACY OF POSITIONING AUTONOMOUS BIOMIMETIC UNDERWATER VEHICLE USING ADDITIONAL MEASUREMENT OF DISTANCES
}

\begin{abstract}
The article describes a study of problem of estimating the position coordinates of Autonomous Biomimetic Underwater Vehicle (ABUV) using two methods: dead reckoning (DR) and extended Kalman filter (EKF). In the first part of the paper, navigation system of ABUV is described and scientific problem with underwater positioning is formulated. The main part describes a way of estimating the position coordinates using DR and EKF and a numerical experiment involving motion of ABUV along the predetermined test distance. The final part of the paper contains a comparative statistical analysis of the results, carried out for assessing the accuracy of estimation of the position coordinates using DR and EKF methods. It presents the generalized conclusions from the research and the problems relating to the proper placement of the components of the system measuring distances.
\end{abstract}

\section{Keywords:}

underwater positioning, estimation of coordinates, autonomous biomimetic underwater vehicle.

\section{INTRODUCTION}

During the process of introducing marine underwater navigation, the accurate positioning becomes a significant problem. It results from the fact that you cannot use the GPS system under the water surface [Ciećko, Grzegorzewski, Oszczak, Ćwiklak, Grunwald, Balint, Szabo, 2015]. In this case, it becomes 
necessary to use navigation system (NS) specialized for the specific conditions of their future use [Bovio, Cecchi, Baralli, 2006], [Mazlan, McGookin, 2012], [Moreno, 2014], [Naus, Wąż, 2016], [Naus, 2015], [Tian, He, Chen, Liu, 2012], [Wang, Chen, Huosheng, $\mathrm{Hu}, \mathrm{Gu}, 2013$ ]. NS used for underwater positioning should have following features:

- should be built from devices performing underwater navigation, preferably relative to the bottom, e.g. a Doppler log;

- should use the data fusion methods for estimating the position coordinates with high accuracy over a long period of time - depending on the types of measured parameters and their navigational accuracy, e.g. a distance, a velocity, etc.

Selection of devices and consequently methods for estimation of the ABUV position should take into account also the operating parameters of the ABUV, e.g. the shape, the size, available space for sensors, applied drive, etc.

Currently, the ABUV imitating marine mammal is designed and built in Polish Naval Academy (PNA) (Fig. 1). Starting from the bow to the tail fin, the ABUV consists of the following modules:

- module with camera and 'looking forward' echosounder ('wet' compartment);

- module of the sensors (in the upper part: USBL, hydromodem and 'looking up' echosounder, in the bottom part: sonar and 'looking down' echosounder 'wet' compartment);

- module of the lateral fins ('dry' compartment);

- module of electronics and batteries (the batteries located in the bottom part can move along the longitudinal axis of the vehicle - the possibility of trimming, two computers PC-104 and power management system mounted in the upper part — the whole compartment is 'dry');

- module of the caudal fin consisting from two segments (the tail fin driven by an electric motor with nominal power $250 \mathrm{~W}$, rotary motion converted into an oscillating motion).

The more important operating parameters of the ABUV, determining the construction of the designed NS are: range of swimming equal to about 2 nautical miles and average velocity of motion equal to $1 \mathrm{~m} / \mathrm{s}$. Based on the assumed parameters mentioned below, several variants of NS have been considered. One of them, described in this publication, is the NS including the four navigation and communication devices as follows:

- Inertial Measurement Unit IMU VN-200 [IMU, 2016];

- electromagnetic log ALIZE [Electromagnetic, 2016]; 
- pressure sensor WIKA S-20 [Pressure, 2016];

- hydromodem MICRON DATA MODEM [Specification, 2016].

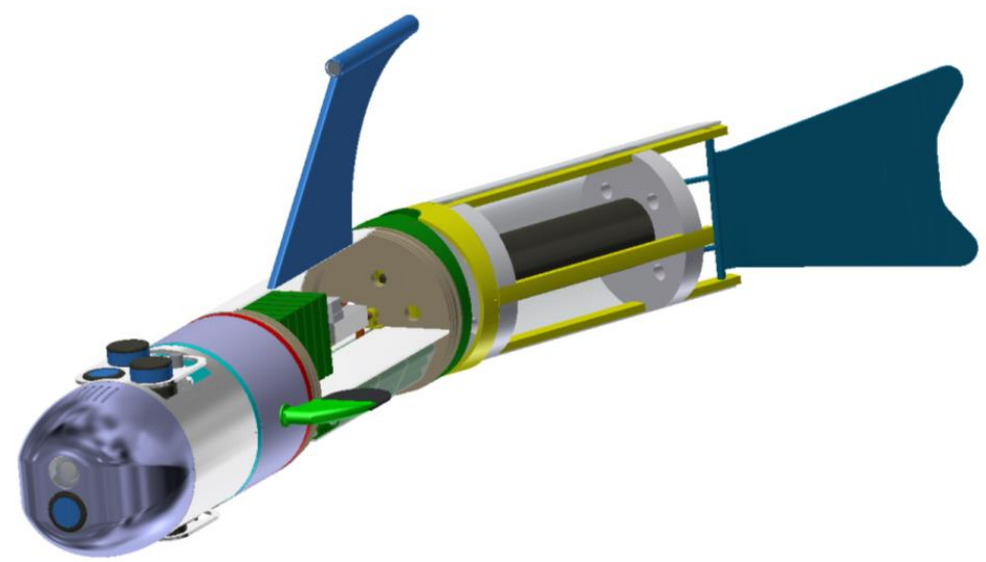

Fig. 1. Side view of 3D model of the ABUV built in Polish Naval Academy

(3D design carried out by Bogdan Szturomski) [Szymak, 2015]

These devices will measure the parameters of motion and distance, which will then be used to calculate the estimated position coordinates ABUV moving underwater with oscillating motion.

\section{FORMULATION OF THE RESEARCH PROBLEM}

We assumed that ABUV swims underwater along the desired trajectory. In the time interval $\tau$, at any time instances $k$ navigational devices installed on the board measure the course over ground $\operatorname{COG}(k)$, speed over ground $\operatorname{SOG}(k)$, change of immersion $\Delta \mathrm{H}(k)$, and in the time instance $k+1$ they measure distances to two hydromodems $\mathrm{D}_{1}(k+1)$ and $\mathrm{D}_{2}(k+1)$. These measurements are subjected to measurement errors with a $99 \%$ probability ( 3 mean errors) within the ranges:

$-\left\langle-15^{\circ}, 15^{\circ}\right\rangle$ for the COG equal to YAW measured by IMU VN-200 (the range was accepted arbitrarily) [IMU, 2016];

- $\langle-1.5 \mathrm{kn}, 1.5 \mathrm{kn}\rangle$ for the SOG equal to STW measured by electromagnetic $\log$ ALIZE (the range responds to 3 mean errors of measurement) [Electromagnetic, 2016]; 
$-\langle-0.15 \mathrm{~m}, 0.15 \mathrm{~m}\rangle$ for the immersion measured by pressure sensor WIKA S-20 (the range responds to 3 mean errors of measurement) [Pressure, 2016];

- $\langle-0.6 \mathrm{~m}, 0.6 \mathrm{~m}\rangle$ for distance $\mathrm{D}$ measured as an additional parameters during underwater communication by means of hydromodems MICRON DATA MODEM (the range responds to 3 mean errors of measurement) [Specification, 2016].

Based on the measurements obtained at each time $k$, we determined the estimated coordinates of the ABUV position in the time interval $\tau$ using dead reckoning method (based on the $\operatorname{COG}(k), \operatorname{SOG}(k), \Delta \mathrm{DIP}(k)$ ) and extended Kalman filter (based on $\operatorname{COG}(k), \operatorname{SOG}(k), \Delta \mathrm{DIP}(k)$, and additionally the distance measurements $\mathrm{D}_{1}(k+1)$ i $\left.\mathrm{D}_{2}(k+1)\right)$.

There occur following questions:

1. Will both methods estimate position coordinates with the same accuracy?

2. Which cases can dead reckoning and extended Kalman filter be used?

These are the questions that the authors try to answer later in this article.

\section{CALCULATION METHOD}

\section{Dead Reckoning DR}

Estimation of position coordinates using the DR were implemented using measurements $\operatorname{COG}(k), \operatorname{SOG}(k)$ and $\triangle \mathrm{DIP}(k)$. Based on the measurements, the vector $\mathbf{x}$ of position coordinates was calculated in the next time instance $(k+1)$, using the function $\mathbf{f}(\mathbf{x}(k), \mathbf{u}(k), \mathbf{w}(k))$ describing the non-linear motion model of the ABUV in 3 degrees of freedom:

$$
\mathbf{x}(k+1)=\left[\begin{array}{l}
f_{x}(k+1) \\
f_{y}(k+1) \\
f_{h}(k+1)
\end{array}\right]=\left[\begin{array}{c}
x(k) \\
y(k) \\
h(k)
\end{array}\right]+\left[\begin{array}{c}
\Delta t(k) \cdot \operatorname{SOG}(k) \cdot \sin \operatorname{COG}(k) \\
\Delta t(k) \cdot \operatorname{SOG}(k) \cdot \cos \operatorname{COG}(k) \\
\Delta \mathrm{DIP}(k)
\end{array}\right]+
$$

$$
+\left[\begin{array}{l}
w_{\mathrm{x}}(k) \\
w_{\mathrm{y}}(k) \\
w_{h}(k)
\end{array}\right],
$$


where:

$x(k), y(k), h(k) \quad$ - calculated position coordinates of the ABUV in the time $t$, $\operatorname{COG}(k) \quad$ - course over ground of the ABUV in the time $k$,

$\operatorname{SOG}(k)$

$\Delta \mathrm{DIP}(k)$

- speed over ground of the ABUV in the time $k$,

$\Delta t(k)$

- change of immersion of the ABUV in the time $k$,

$w_{x}(k), w_{y}(k), w_{h}(k)$ - random disturbances in determining the coordinates (expressed in the form of errors with zero expected value and a normal distribution).

\section{External Kalman Filter EKF}

Estimation of position coordinates by means of EKF were implemented using additional measurements of the distances between the ABUV and two hydromodems (located at the fixed position), performed at different time intervals (in certain moments $k+1)$. Based on the measurements, an observation vector $\mathbf{z}=\left[\mathrm{D}_{1}(k+1) \mathrm{D}_{2}(k+1)\right]^{T}$ was created. The vector was described by the function:

$$
\begin{gathered}
\mathbf{h}(\mathbf{x}(k+1), \mathbf{v}(k+1))=\left[\begin{array}{l}
f_{1}(k+1) \\
f_{2}(k+1)
\end{array}\right]= \\
=\left[\begin{array}{l}
\mathrm{d}_{1}(k+1) \\
\mathrm{d}_{2}(k+1)
\end{array}\right]+\left[\begin{array}{l}
v_{1}(k+1) \\
v_{2}(k+1)
\end{array}\right],
\end{gathered}
$$

where:

$\mathrm{d}_{i}(k+1)=$ $\sqrt{\left(x_{i}(k+1)-x(k+1)\right)^{2}+\left(y_{i}(k+1)-y(k+1)\right)^{2}+\left(h_{i}(k+1)-h(k+1)\right)^{2}}$,

$v_{i}(k+1)$ - errors of the measurement of distances to hydromodem no. $i$ (with zero expected value and normal distribution), $x_{i}(k+1), y_{i}(k+1), h_{i}(k+1)$ - position coordinates of hydromodem no. $i$, where $i$ is 1 or 2 .

Functions: $\mathbf{f}(\mathbf{x}(k), \mathbf{u}(k), 0)$ and $\mathbf{h}(\mathbf{x}(k+1), 0)$ were used for the final determination of the vector $\hat{\mathbf{x}}(k+1)$ of estimated position coordinates of the ABUV using EKF method, according to the algorithm (Fig. 2). 


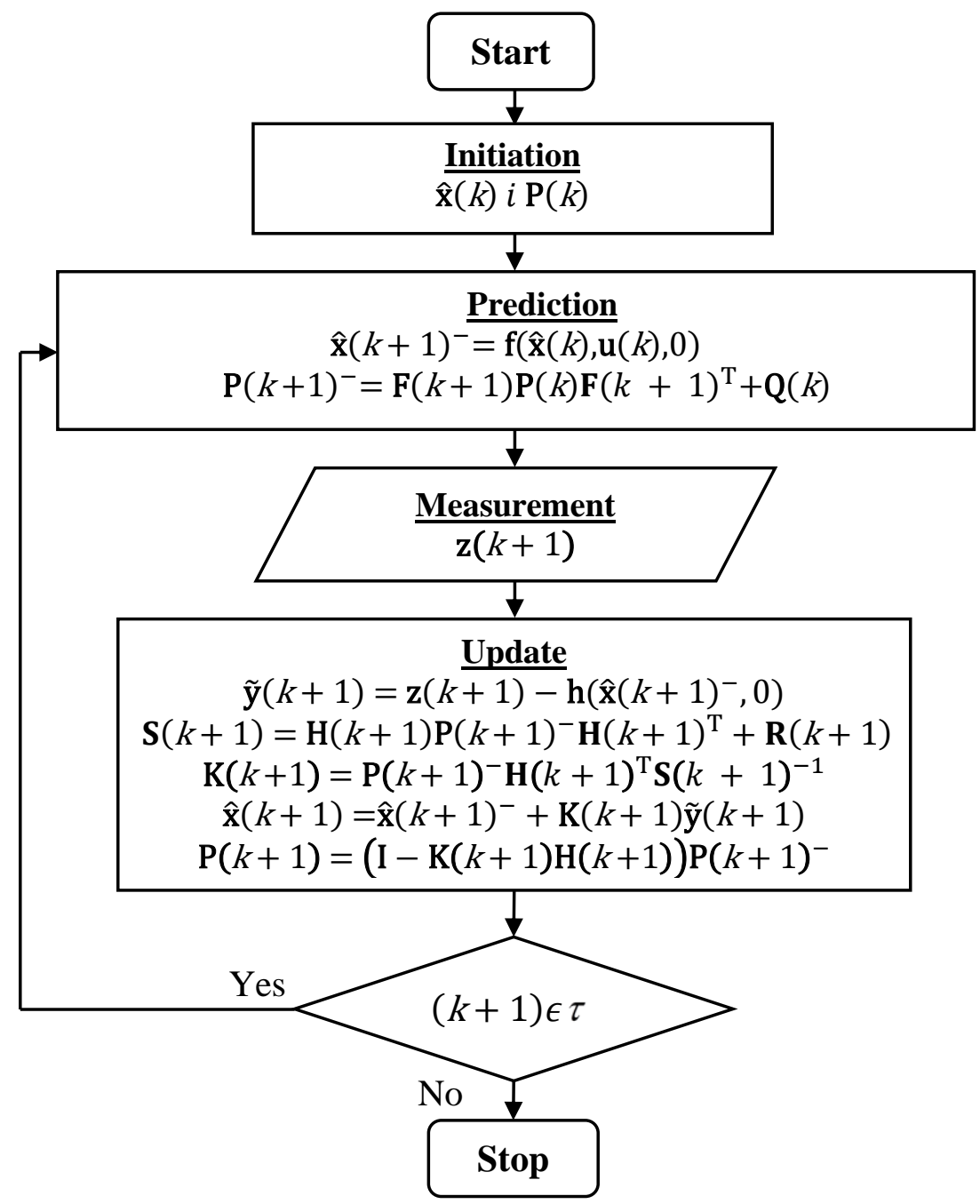

Fig. 2. Algorithm of Extended Kalman Filter

Where:

$\hat{\mathbf{x}}(k+1) i \mathbf{P}(k+1) \quad$ - the vector of estimated coordinates of the ABUV position and its covariance matrix, established a posteriori in the time $k+1$,

$\hat{\mathbf{x}}(k+1)^{-} i \mathbf{P}(k+1)^{-}$- the vector of estimated coordinates of the ABUV position and its covariance matrix, established a priori in the time $k+1$, 
$\mathbf{F}(k+1)=\left[\begin{array}{lll}\frac{\partial f_{x}}{\partial x} & \frac{\partial f_{x}}{\partial y} & \frac{\partial f_{x}}{\partial h} \\ \frac{\partial f_{y}}{\partial x} & \frac{\partial f_{y}}{\partial y} & \frac{\partial f_{y}}{\partial h} \\ \frac{\partial f_{h}}{\partial x} & \frac{\partial f_{h}}{\partial y} & \frac{\partial f_{h}}{\partial h}\end{array}\right]=\left[\begin{array}{lll}1 & 0 & 0 \\ 0 & 1 & 0 \\ 0 & 0 & 1\end{array}\right]$ - the system matrix calculated as the Jacobian matrix of the function: $\mathbf{f}(\mathbf{x}(k), \mathbf{u}(k), 0)$,

$\mathbf{Q}(k)=\left[\begin{array}{lll}\delta_{x}{ }^{2} & \delta_{x y} & \delta_{x z} \\ \delta_{y x} & \delta_{y}{ }^{2} & \delta_{y z} \\ \delta_{z x} & \delta_{z y} & \delta_{z}{ }^{2}\end{array}\right]=$

$=\left[\begin{array}{ccc}\frac{\partial f_{x}}{\partial C O G} & \frac{\partial f_{x}}{\partial S O G} & \frac{\partial f_{x}}{\partial \Delta D I P} \\ \frac{\partial f_{y}}{\partial C O G} & \frac{\partial f_{y}}{\partial S O G} & \frac{\partial f_{y}}{\partial \Delta D I P} \\ \frac{\partial f_{h}}{\partial S O G} & \frac{\partial f_{h}}{\partial C O G} & \frac{\partial f_{h}}{\partial \Delta D I P}\end{array}\right]\left[\begin{array}{ccc}\sigma_{C O G}{ }^{2} & 0 & 0 \\ 0 & \sigma_{S O G}^{2} & 0 \\ 0 & 0 & \sigma_{\Delta D I P}\end{array}\right]\left[\begin{array}{ccc}\frac{\partial f_{x}}{\partial C O G} & \frac{\partial f_{x}}{\partial S O G} & \frac{\partial f_{x}}{\partial \Delta D I P} \\ \frac{\partial f_{y}}{\partial C O G} & \frac{\partial f_{y}}{\partial S O G} & \frac{\partial f_{y}}{\partial \Delta D I P} \\ \frac{\partial f_{h}}{\partial S O G} & \frac{\partial f_{h}}{\partial \mathrm{COG}} & \frac{\partial f_{h}}{\partial \Delta D I P}\end{array}\right]^{\mathrm{T}}-$

disturbances matrix of state vector in the time $k$ (with accepted mean errors $\delta_{C O G}, \delta_{S O G}, \delta_{\triangle D I P}$ of measurement COG, SOG and change of immersion), $\delta_{x}{ }^{2}=\Delta t^{2} \cdot\left(\operatorname{SOG}(k) \cdot \delta_{C O G} \cdot \cos \operatorname{COG}(k)\right)^{2}+\Delta t^{2} \cdot\left(\delta_{S O G} \cdot \sin \operatorname{COG}(k)\right)^{2}$, $\delta_{y}{ }^{2}=\Delta t^{2} \cdot\left(\operatorname{SOG}(k) \cdot \delta_{C O G} \cdot \sin \operatorname{COG}(k)\right)^{2}+\Delta t^{2} \cdot\left(\delta_{S O G} \cdot \cos \operatorname{COG}(k)\right)^{2}$, $\delta_{x y}=\delta_{y x}=\Delta t^{2} \cdot \sin (2 \cdot \operatorname{COG}(k)) \cdot\left(\delta_{S O G}{ }^{2}-\left(S O G \cdot \delta_{C O G}\right)^{2}\right) / 2$, $\delta_{x z}=\delta_{y z}=\delta_{z x}=\delta_{z y}=0$, $\delta_{z}^{2}=\delta_{\Delta D I P}^{2}$, $\mathbf{P}(k)$ - updated covariance matrix of state vector used in the time $k+1$,

$\mathbf{H}(k+1)=\left[\begin{array}{lll}\frac{\partial f_{1}}{\partial x} & \frac{\partial f_{1}}{\partial y} & \frac{\partial f_{1}}{\partial h} \\ \frac{\partial f_{2}}{\partial x} & \frac{\partial f_{2}}{\partial y} & \frac{\partial f_{2}}{\partial h}\end{array}\right]=$

$=\left[\begin{array}{ccc}-\frac{x_{1}(k+1)-x(k+1)}{d_{1}(k+1)} & -\frac{y_{1}(k+1)-y(k+1)}{d_{1}(k+1)} & \frac{h_{1}(k+1)-h(k+1)}{d_{1}(k+1)} \\ -\frac{x_{2}(k+1)-x(k+1)}{d_{2}(k+1)} & -\frac{y_{2}(k+1)-y(k+1)}{d_{2}(k+1)} & \frac{h_{2}(k+1)-h(k+1)}{d_{2}(k+1)}\end{array}\right]-$ Jacobian matrix of the function $\mathbf{h}(\mathbf{x}(k), 0)$, $\mathbf{z}(k+1)=\left[\mathrm{D}_{1}(k+1) \mathrm{D}_{2}(k+1)\right]^{T}$, 
$\mathbf{R}(k+1)=\left[\begin{array}{cc}\sigma_{D}^{2} & 0 \\ 0 & \sigma_{D}^{2}\end{array}\right]$ - disturbances matrix of state vector in the time $k+1$

(with accepted mean error $\sigma_{D}$ of measurement distance to the hydromodems), I - identity matrix.

\section{NUMERICAL RESEARCH WITH ANALYSIS OF THE RESULTS}

The numerical experiment includes simulation of the ABUV swimming along straight section with:

- generation of measurements of COG — performed by IMU VN-200, SOG performed by the log ALIZE and change of immersion achieved from pressure sensor WIKA S-20;

- generation of measurement of distance D - performed by hydromodems MICRON DATA MODEM;

- calculation of estimated coordinates of the ABUV position using DR and EKF methods.

As a testing ground, a maritime area in the shape of a rectangle with a length of about $600 \mathrm{~m}$ was accepted (Fig. 3).

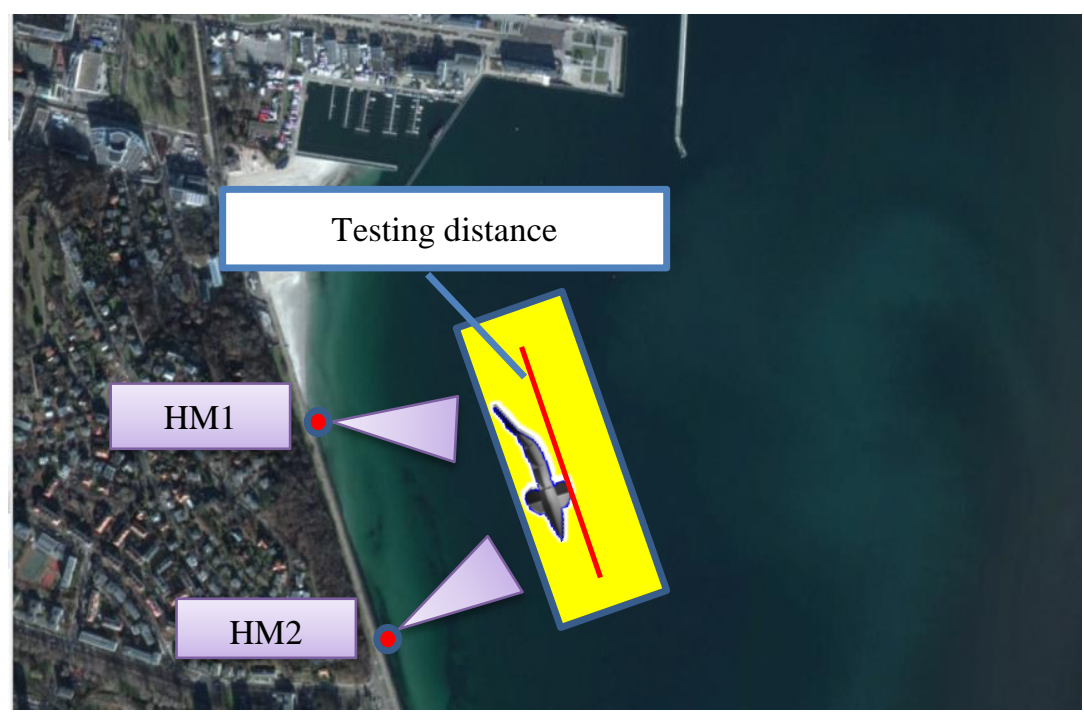

Fig. 3. Testing ground [used application Google Maps] 
Let the ABUV to swim with constant $\mathrm{COG}=160^{\circ}$ and constant SOG = $1 \mathrm{~m} / \mathrm{s}$, with constant immersion equal to $4 \mathrm{~m}$. At the time $\tau=\langle 0 \mathrm{~s}, 600 \mathrm{~s}\rangle$ measurements were performed by the devices mounted on board of the ABUV, i.e.:

- at the predetermined moments of time $k+1$ (per 1 second) $\operatorname{COG}(k+1)=$ $\mathrm{COG}_{w}(k+1)+\Delta_{\delta_{C O G}}, \operatorname{SOG}(k+1)=\operatorname{SOG}_{w}(k+1)+\Delta_{\delta_{S O G}}$ and $\Delta \mathrm{DIP}(k+1)=$ $\Delta \mathrm{DIP}_{w}(k+1)+\Delta_{\delta_{\Delta D I P}}$

- in certain moments of time $k+1$ (per 10,60,100 seconds) distances $\mathrm{D}_{1}(k+1)=$ $\mathrm{D}_{w 1}(k+1)+\Delta_{\delta_{D}}, \mathrm{D}_{2}(k+1)=\mathrm{D}_{w 2}(k+1)+\Delta_{\delta_{D}}$ to 2 hydromodems $\mathrm{HM}_{1}, \mathrm{HM}_{2}$.

Each simulated value of the measurement was obtained as a sum of the reference measurement and the random correction (e.g. simulated $\operatorname{COG}(k+1)=$ $\left.\mathrm{COG}_{w}(k+1)+\Delta_{\delta_{C O G}}\right)$. Correction $\Delta$ was treated as a random variable with uniform distribution, whose the value was in the range of 3 mean errors $3 \delta$ of measurements carried out by the specific measurement device.

Reference distances $\mathrm{D}_{1}(k+1), \mathrm{D}_{2}(k+1)$ were referenced to the subsequent positions of the ABUV swimming with undisturbed movement. These positions were calculated by DR method, based on the reference course $\mathrm{COG}_{w}(k+1), \mathrm{SOG}_{w}(k+1)$ and $\Delta \mathrm{DIP}_{w}(k+1)$ - i.e. they were located exactly at the testing distance.

To make experiment more realistic, the values of mean error of measurement close to the real values were accepted (provided by the manufacturer and designated based on the own research — accepted arbitrarily):

$-\delta_{C O G}=5^{\circ}$ - for IMU VN-200;

$-\delta_{S O G}=0.5 \mathrm{kn}$ - for electromagnetic log ALIZE;

$-\delta_{\triangle D I P}=0.05 \mathrm{~m}$ - for pressure sensor WIKA S-20;

- $\delta_{D}=0.2 \mathrm{~m}$ - for hydromodem MICRON DATA MODEM.

The experiment were initiated at the moment $k=0$ and were ended when the ABUV swam about $600 \mathrm{~m}$. At the beginning of the experiment extended Kalman filter were 'tuned' and the coordinates of the starting position of the ABUV were determined with an mean error equal to $3 \mathrm{~m}$ (e.g. determinated by GPS/SBAS receiver [IMU VN-200] before immersion of the ABUV). In these calculations, changes of COG, SOG i $\triangle$ DIP caused by oscillating motion (along a sine curve) of the ABUV were omitted.

\section{Test No. 1}

The test consisted of three, and then one hundred of passes along the testing section. COG, SOG i $\triangle$ DIP were measured per 1 second. 
$\mathrm{D}_{1}, \mathrm{D}_{2}$ were measured per 100 seconds.

In the Figures 4 and 5 graphs of simulated COG and SOG during first testing pass were presented.

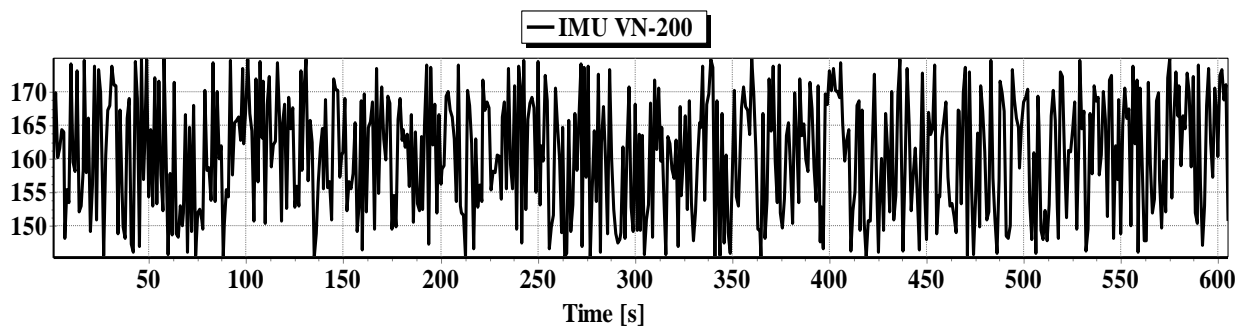

Fig. 4. Simulated COG during first testing pass

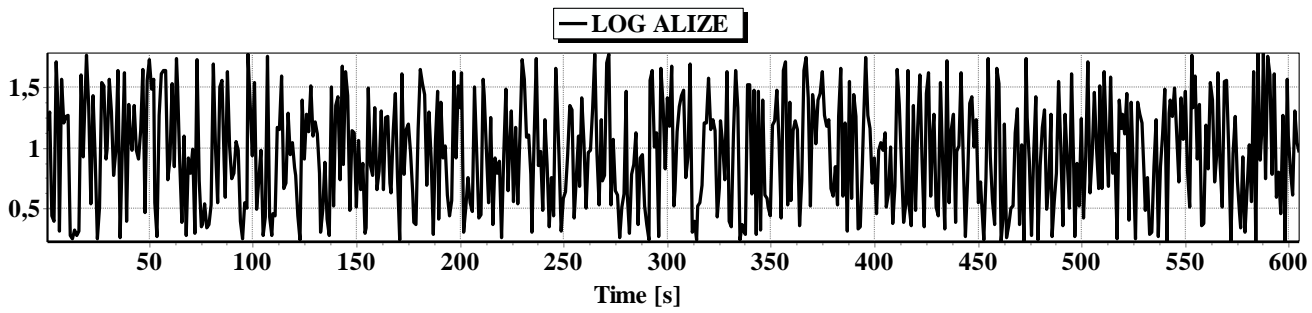

Fig. 5. Simulated SOG during first testing pass

The Figures 4 and 5 show clearly that the dispersion of the measurements is a random and limited. COG values oscillate around the reference $\mathrm{COG}_{w}=160^{\circ}$ and they does not exceed $15^{\circ}(<3 \delta)$. Likewise, SOG values oscillate around the referenceSOG ${ }_{w}=1 \mathrm{~m} / \mathrm{s}$ and they do not exceed $0.75 \mathrm{~m} / \mathrm{s}(<3 \delta)$.

In the Figure 6, the two courses in time of distance of reference position and estimated position achieved by means of DR and EKF methods are included to compare these two methods.

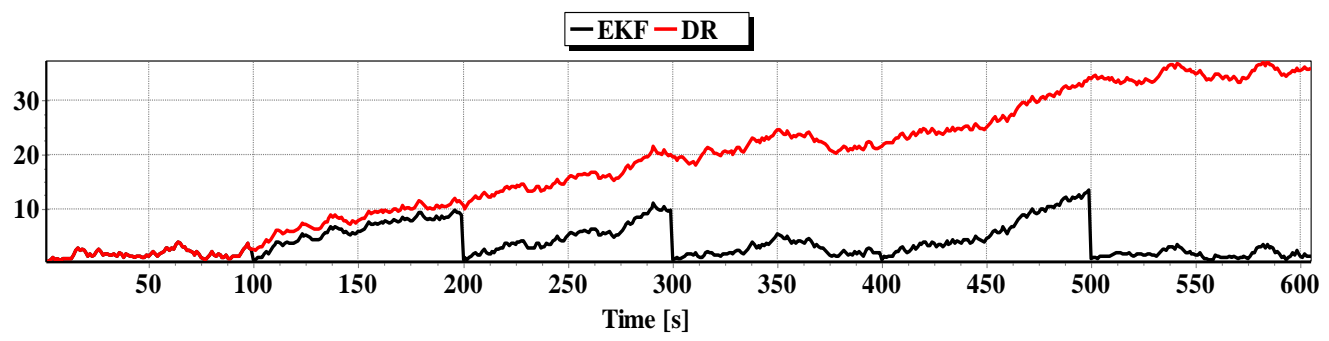

Fig. 6. Distance of reference position and estimated position during first testing pass 
The Figure 6 shows that the accuracy of position coordinates improved significantly per 100 seconds. These are the moments used to calculate additional distance measurements $\mathrm{D}_{1}(k+1)$ and $\mathrm{D}_{2}(k+1)$.

Based on the measurements collected during two consecutive passes along the test section, two next graphs of distance of reference position and estimated position are presented in the Figures 7 and 8 .

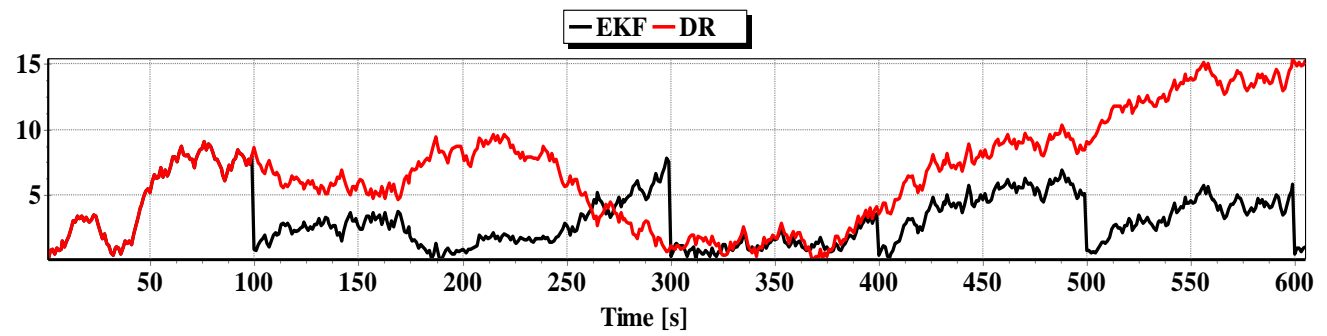

Fig. 7. Distance of reference position and estimated position during second testing pass

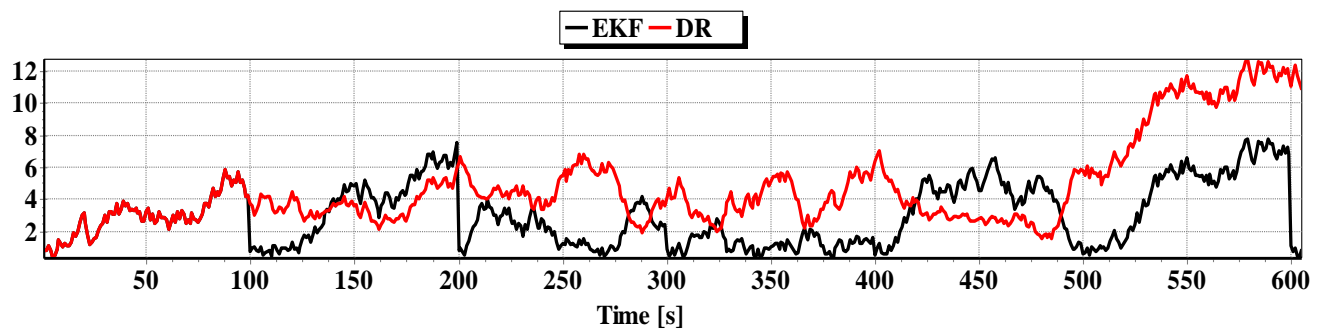

Fig. 8. Distance of reference position and estimated position during third testing pass

The graphs shows that the accuracy of the estimated coordinates of position using EKF method was greater than the estimated coordinates of position achieved by means of DR method. The estimated position by EKF is located from the reference position not farther than $8 \mathrm{~m}$. Unfortunately, it can be also noted on the graphs that there were time intervals $\langle 148 \mathrm{~s}, 200 \mathrm{~s}\rangle$ and $\langle 443 \mathrm{~s}$, $481 \mathrm{~s}\rangle$, in which the reference position was located from the estimated by EKF method farther than for the position estimated by the DR method. So there are arising the following question: how often these time intervals may be? The answer to this question can be given in the results of the additional statistical analyzes. The authors decided on two analyzes. The first analysis was based on the average distance of the reference position $\xi$ to the estimated position, calculated based on the $n$ distances $\zeta$ obtained in $n$ passes along test section, according to the formula: 


$$
\xi(k)=\sum_{i=0}^{n} \zeta(k)
$$

Figure 9 show a graph of the average distance to the reference position from the estimated position, based on one hundred of distance measurements made at the same time in each of the hundred passes of the ABUV along the test section.

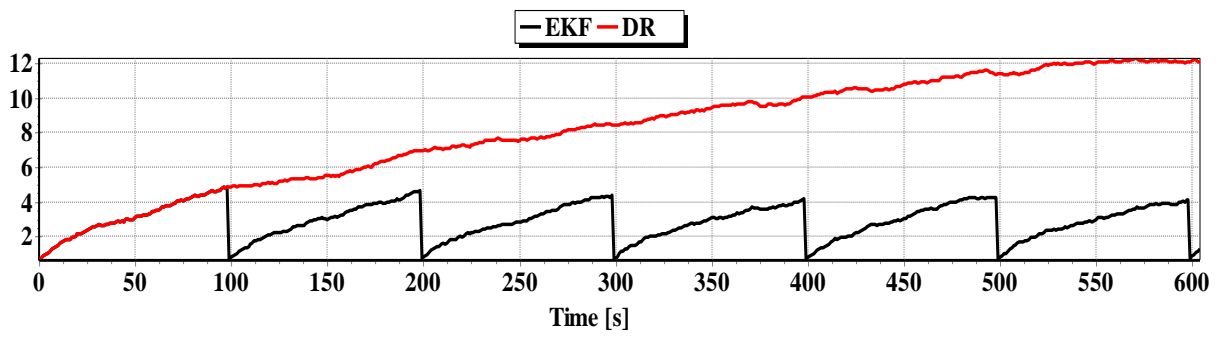

Fig. 9. Average distance $\xi$ to the reference position from the estimated position based on one hundred passes along the test section

The average value of the distance to the reference position from the estimated position increased linearly. The maximum value of the average distance was about 12 meters - in the case of using the DR method and $5 \mathrm{~m}$ - in the case of using the EKF method.

The second statistical analysis was based on a histogram showing the incidence of the same distances to the reference position from the estimated position achieved by EKF and DR methods.

\section{EKF DDR}

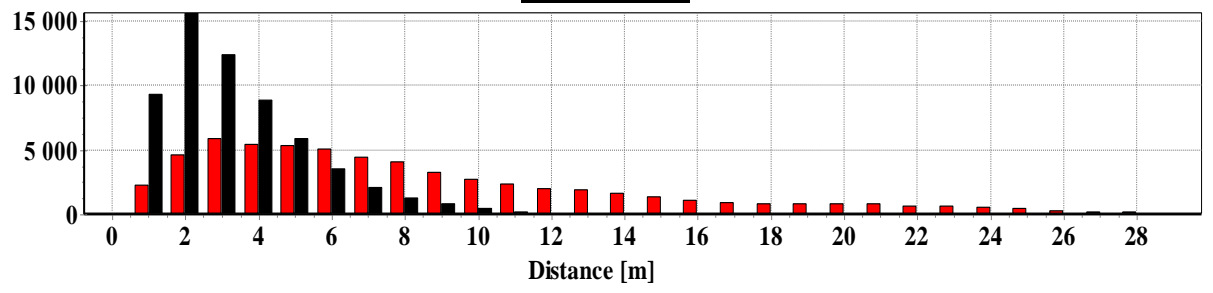

Fig. 10. Histogram of distance to the reference position from the estimated position based on the one hundred passes along the test section 
The histogram shows that the distances to the reference position from the estimated position achieved by EKF equal to 2 meter occurred the most often. Significant changes in the distance persisted with greater frequency in the case of the positions estimated by the DR method.

\section{Test No. 2}

The test depended on performing one hundred passes along the test section. COG, SOG i $\triangle \mathrm{DIP}$ were measured per 1 second. $\mathrm{D}_{1}, \mathrm{D}_{2}$ were measured per 60 seconds.

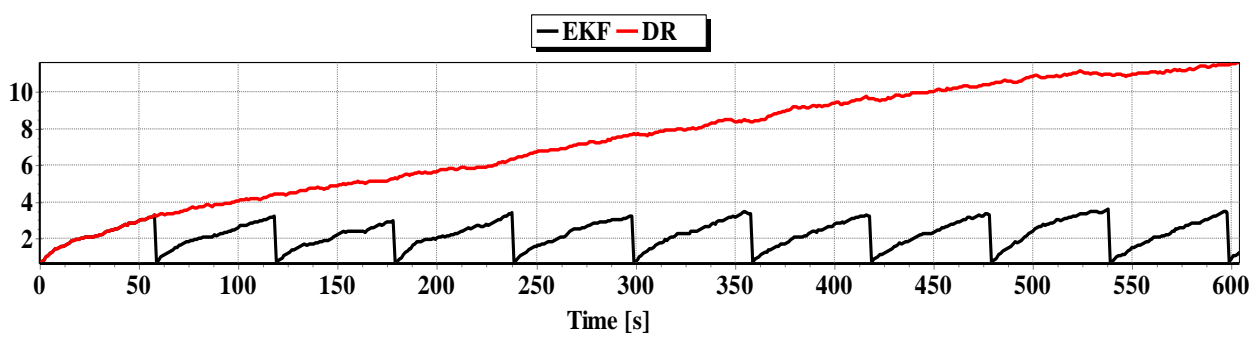

Fig. 11. Average distance $\xi$ to reference position from estimated position based on 100 passes along the test section

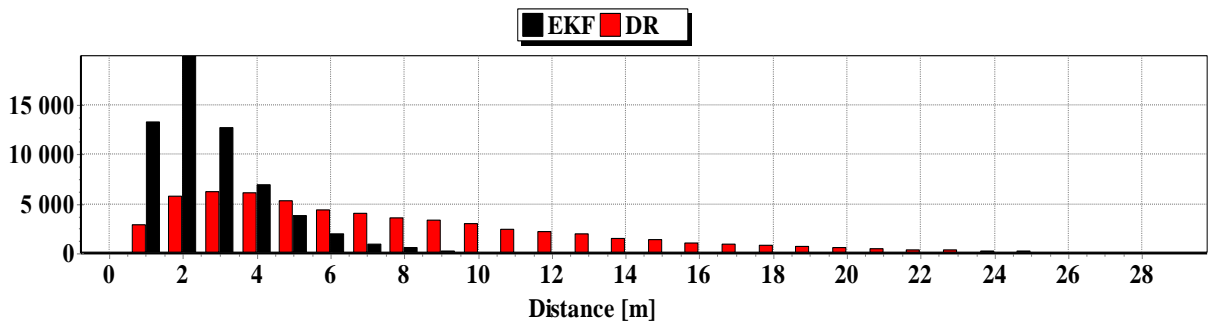

Fig. 12. Histogram of distance to the reference position from the estimated position based on the 100 passes along the test section

The analysis of the results obtained in the test No. 2 indicated that they were similar to those obtained in test No. 1, except achieved accuracy of the estimated position coordinates by the EKF method. It can be seen that the accuracy obtained in the test No. 2 was significantly higher than the accuracy achieved in the test No. 1.

\section{Test No. 3}

The test depended on performing one hundred passes along the test section. COG, SOG i $\triangle$ DIP were measured per 1 second. $\mathrm{D}_{1}, \mathrm{D}_{2}$ were measured per 10 seconds. 


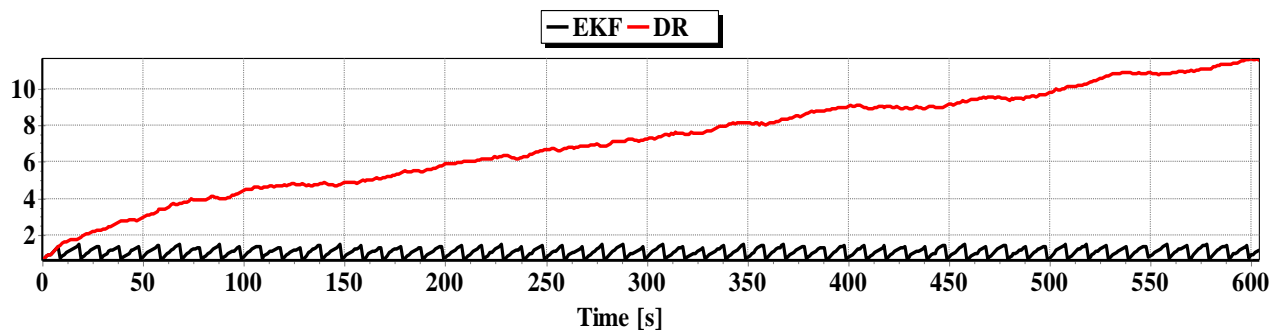

Fig. 13. Average distance $\xi$ to reference position from estimated position based on 100 passes along the test section

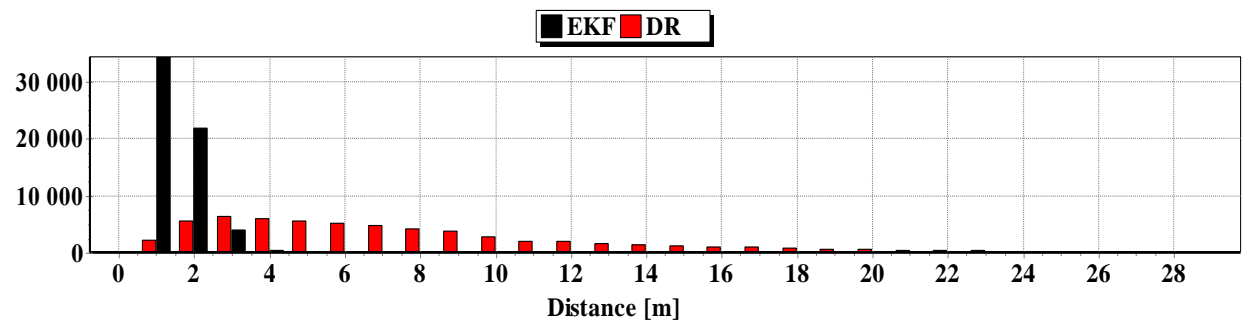

Fig. 14. Histogram of distance to the reference position from the estimated position based on the 100 passes along the test section

The analysis of the results obtained in test No. 3 showed that they were also similar to those obtained in tests No. 1 and 2, except the obtained accuracy of the estimated position coordinates by the EKF method. Average distance $\xi$ to the reference position from the estimated position achieved by the EKF method did not exceed $0.75 \mathrm{~m}$. The incidence of distances up to $2 \mathrm{~m}$ was also dominant for the EKF method.

\section{CONCLUSIONS}

Based on the obtained results it can be stated that the use of additional distance measurements using hydromodems can significantly improve the accuracy of determination of coordinates of the ABUV position. The Extended Kalman Filter seems to be a good solution available for this purpose. It allows you to connect measurements performed by the devices located on the board of the ABUV (log, IMU, pressure sensors) with measurements of distances carried out by external devices (hydromodems) to correct less accurate measurements COG, 
SOG, $\triangle$ DIP by more accurate measurements $\mathrm{D}_{1}, \mathrm{D}_{2}$. The only condition is that the hydroacoustic channel should be available.

In the proposed method, the good localization of the hydromodems in relation to the ABUV is very important, because it can significantly affect the accuracy of the position coordinates (this issue was not discussed in the article) [Naus, 2010], [Naus, 2011], [Naus, Wąż, 2011], [Naus, Narloch, 2014]. In the experiment we accepted the 'good' (but not optimal) localization of the hydromodems HM1 and HM2 in relation to the test section. Position lines obtained from the distances (circles) do not intersect at acute angles.

This ensures that the fluctuation bands and the errors figure of position coordinates calculated based on these bands are relatively small (i.e. the coordinates are more accurate for the same values of measurement errors of navigational parameters).

\section{REFERENCES}

[1] Bovio E., Cecchi D., Baralli F., Autonomous underwater vehicles for scientific and naval operations, 'Annual Reviews in Control', 2006, No. 30, pp. 117-130.

[2] Ciećko A., Grzegorzewski M., Oszczak S., Ćwiklak J., Grunwald G., Balint J., Szabo S., Examination of EGNOS Safety-of-Live Service in Eastern Slovakia, 'Annual of Navigation', 2015, No. 22, pp. 65-79.

[3] Electromagnetic speed log Alize specification [online], http://www.benmarine.fr/files/ ALIZE_en.pdf [access 20.03.2016].

[4] Felski A., Nowak A., Woźniak T., Accuracy and availability of EGNOS — results of observations, 'Artificial Satellites', 2011, Vol. 46, No. 3.

[5] IMU VN-200 user manual [online], http://www.vectornav.com [access 20.03.2016].

[6] Mazlan A. N. A., McGookin E., Modelling and Control of a Biomimetic Autonomous Underwater Vehicle. In Proc. International Conference on Control, Automation, Robotics \& Visions, Guangzhou 2012, China, pp. 88-93.

[7] Moreno D., An object oriented Matlab framework for underwater SLAM using side scan sonar, 'Actas de las XXXV Jornadas de Automática', 2014, Valencia, Spain, pp. 6-14.

[8] Naus K., Evaluation of accuracy the position of the vessel designated stereoscopic cameras system, 'Reports on Geodesy', 2010, No. 1 (88), pp. 79-87.

[9] Naus K., Accuracy in fixing ship's positions by CCD camera survey of horizontal angles, 'Geomatics and Environmental Engineering', 2011, Vol. 5/4, pp. 47-61.

[10] Naus K., Wąż M., Accuracy in fixing ship's positions by camera survey of bearings, 'Geodesy and Cartography', 2011, Vol. 60, No. 1, pp. 61-73. 
[11] Naus K., Narloch A., Distribution of the accuracy of position coordinates fixed using coastal navigation methods against two and three navigational markers, 'Logistyka', 2014, No. 3, pp. 4606-4614.

[12] Naus K., Electronic navigational chart as an equivalent to image produced by hypercatadioptric camera system, 'Polish Maritime Research', 2015, Vol. 22, No. 1 (85), pp. 3-9.

[13] Naus K., Wąż M., Precision in determining ship position using the omnidirectional map to visual shoreline image comparative method, 'Journal of Navigation', 2016, Vol. 69, Issue 02, pp. 391-413.

[14] Pressure sensor WIKA S-20 specification, [online], http://www.przetworniki24.pl/pl/ katalog/przetworniki_cisnienia/S_20 [access 20.03.2016].

[15] Specification of Hydromodem Micron Data Modem, [online], http://www.tritech.co.uk/ product/micron-data-modem [access 20.03.2016].

[16] Szymak P. et al., Report on stage no 2 from development project no. DOBR-BIO4/ 033/13015/2013 entitled 'Autonomous underwater vehicle with silent undulating propulsion for underwater ISR', Polish Naval Academy, Gdynia 2015.

[17] Tian S., He B., Chen S., Liu G., Application of forward-looking scanning sonar on Simultaneous Localization and Mapping for an Autonomous Underwater Vehicle, In Proc. ICCEE International Conference on Computer and Electrical Engineering, Singapore 2012, Vol. 53, No. 2.02, pp. 28-35.

[18] Wang S., Chen L., Huosheng Hu H., Gu D. Single, Beacon based localization of AUVs using moving horizon, In Proc. IEEE/RSJ International Conference on Intelligent Robots and Systems (IROS), Tokyo 2013, pp. 885-900.

Received April 2016

Reviewed October 2016

\section{KRZYSZTOF NAUS}

Polish Naval Academy

Śmidowicza 69 Str., 81-127 Gdynia, Poland

e-mail: k.naus@amw.gdynia.pl

\section{PIOTR SZYMAK}

Polish Naval Academy

Śmidowicza 69 Str., 81-127 Gdynia, Poland

e-mail: p.szymak@amw.gdynia.pl

\section{STRESZCZENIE}

W artykule przedstawiono opis badań dokładności estymowania współrzędnych pozycji ABUV (Autonomous Biomimetic Underwater Vehicle) metodą zliczania drogi (dead 
reckoning - DR) oraz rozszerzonym filtrem Kalmana (external Kalman filter - EKF). W pierwszej części przybliżono tematykę systemów nawigacyjnych ABUV i sformułowano problem naukowy związany z pozycjonowaniem podwodnym. W części głównej opisano sposób estymowania współrzędnych pozycji metodą DR i EKF oraz eksperyment badawczy polegający na programowym symulowaniu przejścia ABUV po zadanym odcinku testowym. Część końcowa zawiera porównawczą analizę statystyczną otrzymanych wyników prowadzoną pod kątem oceny dokładności estymowania współrzędnych pozycji metodami DR i EKF. Przedstawiono w niej także uogólnione wnioski z badań oraz problemy związane z właściwym rozmieszczeniem elementów systemu pomiarowego odległości. 